\title{
Resíduos da construção civil: cenário atual, planejamento e propostas para o município de Macaé, RJ - Brasil
}

\author{
Caroline Ramos Medeiros'; José Augusto Ferreira da Silva²; Marcos Antônio Cruz Moreira²; \\ Frank Pavan de Souza ${ }^{3}$ \\ $\bowtie$ jasilva@iff.edu.br \\ 1. Prefeitura Municipal de Macaé - RJ, Brasil 2. Instituto Federal Fluminense - IFF, Macaé - RJ, Brasil \\ 3. Institutos Superiores de Ensino do CENSA - ISECENSA, Campos dos Goytacazes - RJ, Brasil
}

Histórico do Artigo:

Recebido em: 12 de abril de 2018

Aceito em: 11 de julho de 2018

Publicado em: 28 de dezembro de 2018

Resumo: A indústria da construção civil representa um dos maiores setores da economia mundial responsável por um alto consumo de recursos naturais, por isso tornam-se imprescindíveis alternativas sustentáveis visando à preservação ambiental e o estímulo à reciclagem de resíduos. Buscou-se nesta pesquisa um reconhecimento do cenário atual do município de Macaé, Rio de Janeiro, Brasil em relação aos resíduos de construção civil (RCC) por meio de levantamento bibliográfico, realização de entrevistas e visitas de campo. Apesar de haver beneficiamento desses resíduos no município, ainda se observou o descarte inadequado em 311 pontos na área urbana. 0 quantitativo dos RCC's destinados aos aterros de inertes foi aproximadamente $50 \%$ menor do que o previsto nas estimativas de resíduos gerados pelas obras regularizadas nos anos analisados indicando a necessidade do aprimoramento de políticas de gestão desses resíduos.

Palavras-chave: reciclagem, resíduos de construção civil, gestão pública.

\section{Waste construction: current scenario, planning and proposals for the city of Macaé, RJ - Brazil}

Abstract: The construction industry represents one of the largest sectors of the world economy responsible for a high consumption of natural resources, so sustainable alternatives are essential to environmental preservation and the encouragement of waste recycling. This research aimed to identify the current scenario of the Municipality of Macaé, Rio de Janeiro, Brazil in relation to construction waste (CW) by means of a bibliographic survey, interviews and field visits. Despite the fact that this waste was processed in the municipality, it was still observed the inappropriate disposal in 311 points in the urban area. The amount of CW destined for landfills was approximately $50 \%$ lower than predicted in the estimates of waste generated by the works regularized in the years analyzed, indicating the need to improve the management of this waste.

Keywords: recycling, construction waste, public management. 


\section{Residuos de la construcción civil: escenario actual, planificación y propuestas para el municipio de Macaé, RJ - Brasil}

Resumen: La industria de la construcción civil representa uno de los mayores sectores de la economía mundial responsable de un alto consumo de recursos naturales, por lo que se hacen imprescindibles alternativas sostenibles para la preservación ambiental y el estímulo al reciclado de residuos. Se buscó en esta investigación un reconocimiento del escenario actual del municipio de Macaé, Río de Janeiro, Brasil en relación a los residuos de construcción civil (RCC) por medio de levantamiento bibliográfico, realización de entrevistas y visitas de campo. A pesar de haber beneficiado de esos residuos en el municipio, aún se observó el descarte inadecuado en 311 puntos en el área urbana. El cuantitativo de los RCC para los vertederos de inertes fue aproximadamente un $50 \%$ menor que el previsto en las estimaciones de residuos generados por las obras regularizadas en los años analizados, indicando la necesidad del perfeccionamiento de políticas de gestión de esos residuos.

Palabras clave: reciclaje, residuos de construcción civil, gestión pública.

\section{INTRODUÇÃ0}

A indústria da construção civil representa um dos maiores setores da economia mundial, pois proporciona a geração de emprego e renda, além do desenvolvimento de infraestrutura para os demais segmentos. Por outro lado, diante do alto consumo de recursos naturais, este setor precisa alcançar 0 equilíbrio entre a produtividade e 0 atendimento aos objetivos globais para o desenvolvimento sustentável (SOUZA, 2014).

Diante da necessidade de diminuir custos e otimizar a geração de lucros, o correto gerenciamento dos RCC's, proporciona além dos benefícios ambientais uma oportunidade de compatibilizar a atividade produtiva com a sustentabilidade. A relação custo-benefício entre outros fatores tem contribuído para políticas de reaproveitamento desses resíduos como matéria prima para a construção (NASCIMENT0 et al., 2015).

Esses resultados podem ser alcançados a partir de alguns dos objetivos da Política Nacional de Resíduos Sólidos (PNRS) que correspondem a não geração, redução, reutilização e reciclagem dos resíduos (BRASIL, 2010). Mas apesar de existirem consideráveis avanços em todo o país, algumas regiões ainda precisam enfrentar uma mudança na mentalidade tanto do setor público quanto no privado.

Uma pesquisa realizada em 2014 pela Associação Brasileira de Empresas de Limpeza Pública e Resíduos Especiais (ABRELPE) indicou que foram coletadas 45 milhões de toneladas de RCC's no referido ano, havendo um aumento de 4,1\% em relação ao ano anterior. Tal 
tendência tem sido observada ao longo dos anos, sendo que a quantidade total desses resíduos é ainda maior, pois as prefeituras coletam apenas de obras sob sua responsabilidade e logradouros públicos (ABRELPE, 2014).

Diante deste cenário, iniciativas de reciclagem surgem como alternativas para a gestão adequada desses resíduos, os quais possuem um potencial rentável para serem reintroduzidos na cadeia de produção (BERNARD0 et al., 2016). Estudos realizados por Frasson e Filho (2015) comprovam a viabilidade econômica da reciclagem dos RCC's no próprio local de geração proporcionando a redução dos custos na aquisição de matéria prima, no transporte dos resíduos e na disposição final.

Bovea e Powell (2016) apontam as diferenças quanto ao gerenciamento dos resíduos nas obras considerando as peculiaridades dos processos realizados dentro e fora do local de geração. Nas demolições, por exemplo, quando a triagem ocorre no local é necessária a desconstrução parcial da edificação e a segregação das frações. Neste caso, requer-se mais energia no processo, porém é possível obter materiais de melhor qualidade para destinação à reciclagem. Para as triagens realizadas fora do local de geração, tanto nas construções, quanto nas demolições, deve-se considerar o consumo de energia para o transporte dos resíduos e segregação em frações recicláveis.

Araújo et al. (2016) demonstraram a possibilidade de substituição de até 100\% dos agregados naturais pelos reciclados na confecção de concreto estrutural, apesar de as normas brasileiras não permitirem esse tipo de aplicação. Os resultados não indicaram prejuízos das resistências à compressão e à tração do concreto, entretanto para isso é necessário garantir a qualidade dos agregados a serem utilizados.

As propriedades físicas dos agregados reciclados não dependem apenas do tipo de material reciclado, mas também são influenciadas pelo processo de fabricação adotado (CARDOSO et al., 2016). Por isso, ações permanentes para o alcance da gestão mais criteriosa desses resíduos são de extrema relevância.

A geração dos RCC’s é inevitável durante o processo de expansão urbana, consolidação das cidades e nos períodos de maturidade, onde se iniciam a renovação das edificações (MEL0 et al., 2011).

No município de Macaé, até a década de 70 a economia era baseada nas atividades de agricultura, pecuária e pesca. Entretanto, a partir deste período a cidade vivencia um novo cenário diante da descoberta do petróleo na Bacia de Campos impulsionando a economia e a expansão demográfica (MACAÉ, 2016). 0 município é conhecido como a "Capital Nacional do 
Resíduos da construção civil: cenário atual, planejamento e propostas para o município de Macaé, RJ - Brasil

Petróleo", por onde passam $80 \%$ do petróleo e $50 \%$ do gás natural produzidos no país. A evolução da indústria do petróleo contribuiu com o aumento populacional e um crescimento econômico de 600\% em 10 anos. Macaé destaca-se como um dos principais polos de desenvolvimento econômico no Estado, recebendo também investimentos no turismo, agronegócio e construção civil (MACAÉ, 2012).

Esse crescimento aumentou consideravelmente a geração de resíduos, correspondendo a 89 t/dia acima das estimativas realizadas para a implantação do aterro sanitário no município. Tal cenário contribui para a diminuição da vida útil do aterro, podendo ocasionar problemas ao ambiente (DIAS, 2011).

A pesquisa tem como objetivo avaliar a gestão dos RCC's no município de Macaé abordando as atuais práticas adotadas no gerenciamento desses resíduos e os seus resultados práticos, diagnosticando os pontos de descarte irregular e propondo iniciativas para saneamento ambiental desses locais.

No município de Macaé, não há plano específico para o gerenciamento dos RCC's o que existem são as leis municipais que vedam o descarte de lixo doméstico e entulhos nos logradouros públicos (Lei ${ }^{0}$ 3.371/2010) e a previsão de coleta e distribuição de sobras de material de construção à população carente (Lei nº 3.743/2012). A Lei nº 3.852/2012 estabelece os objetivos, princípios e instrumentos para o Plano Municipal de Gerenciamento de Resíduos Sólidos e prevê a revisão a cada dois anos.

De acordo com pesquisas da ABREC0N (2015), 56\% dos municípios brasileiros que realizam a reciclagem dos RCC's possuem Planos de Gerenciamento de Resíduos, entretanto, em apenas 40\% está previsto o uso preferencial de agregados reciclados em pavimentos de base e sub-base em obras públicas. A inexistência de mecanismos de incentivo para utilização de materiais reciclados tanto em obras públicas quanto privadas dificulta a inserção desses produtos no mercado.

\section{MATERIAL E MÉTODOS}

0 município de Macaé está localizado na Região Norte do estado brasileiro do Rio de Janeiro sendo dividido em seis distritos: Sede, Córrego do Ouro, Cachoeiros de Macaé, Glicério, Frade e Sana, totalizando uma área de 1.216,84 km² de extensão (IBGE, 2016; MACAÉ, 2012). Para 
esta pesquisa considerou-se a zona urbana, conforme o novo reordenamento territorial do município estabelecido pela Lei Complementar Municipal (LCM) nº 214/2012.

A pesquisa foi baseada nos métodos empírico-fenomenológico de características exploratória-descritiva, por meio de entrevistas qualificadas com gestores responsáveis pelo gerenciamento dos RCC’s municipais e carroceiros que utilizam transporte de tração animal para o recolhimento desses resíduos, pesquisa bibliográfica e documental. A partir de então foi realizada uma avaliação a respeito da gestão e gerenciamento dos RCC's na área urbana do município de Macaé.

Além do levantamento bibliográfico a partir de trabalhos nacionais e internacionais sobre os resíduos provenientes das atividades de construção civil, foram coletadas informações nos aterros localizados no município objeto de estudo e licenciados para 0 recebimento desses resíduos. Tais informações referem-se ao quantitativo de RCC's destinados a estes locais durante os anos de 2014, 2015 e parte de 2016. Foi possível realizar uma visita técnica à unidade de beneficiamento de RCC's da Zadar, empresa contratada pela prefeitura e responsável pelo recebimento e destinação final ambientalmente adequada desses resíduos recolhidos por demais empresas gerenciadoras particulares.

A estimativa da geração de resíduos foi calculada apenas a partir de obras regulares, para isso foram consultados os alvarás de construção e demolição emitidos pela Secretaria Municipal de Obras Públicas (SEMOB) durante os anos de 2014, 2015 e até o mês de junho de 2016.

Em relação à área total construída das edificações, para o cálculo das estimativas mensais de geração de resíduos ao longo dos anos foi utilizada a equação (l) proposta por Pinto (1999), conforme também utilizado por Ângulo (2011). A partir de então é possível quantificar a massa de resíduos por mês, multiplicando-se a área total construída por um índice de geração de RCC.

$$
\mathrm{C}=\mathrm{A}_{\mathrm{C}} \times \rho_{\mathrm{C}}
$$

Onde:

C: resíduo na construção por mês (t RCC/mês);

Ac: área construída por mês ( $\mathrm{m}^{2}$ construídos/mês);

$\rho C$ : índice de geração de resíduo na construção $(0,150$ t RCC/m² construído) 
Resíduos da construção civil: cenário atual, planejamento e propostas para o município de Macaé, RJ - Brasil

De acordo com Pinto (1999) a formulação deste indicador considera a taxa de construções formais a partir de dados obtidos em registros públicos de licenciamento e informações obtidas a partir de pesquisas com agentes coletores, sendo este último em relação às obras informais. 0 índice também é composto pela estimativa de geração de resíduos por metro quadrado com base na massa estimada para as edificações construídas por processos convencionais e na perda média de materiais.

Em relação aos dados dos alvarás de demolição não foram encontrados trabalhos nacionais para estimar a geração de resíduos nestas atividades, por isso foi utilizada a taxa de $1.129 \mathrm{~kg}$ de RCC por metro quadrado de área demolida observada por Llatas (2011) a partir das informações do Plano Nacional Integrado de Resíduos da Espanha.

0 mapeamento dos pontos de descarte irregular de RCC foi realizado por meio de saídas de campo durante os meses de janeiro a junho de 2016, utilizando-se o GPS modelo Garmim Oregon 600 e máquina para registro fotográfico dos locais. E, considerando-se a extensão territorial da área de estudo, a identificação dos demais pontos foi realizada por interpretação de imagens de satélite das áreas com o Programa Google Earth Pro, obtidas no ano de 2016. Para a produção do mapeamento utilizou-se o software ArcGis (ESRI), versão Trial adquirida individualmente.

\section{RESULTADOS E DISCUSSÃ0}

No município de Macaé, os serviços de limpeza urbana são prestados por empresa terceirizada por meio do contrato administrativo $n^{0}$ 007/2011. Sendo assim, a empresa Limpatech Tecnologia de Limpeza é a responsável pelas operações de coleta, remoção e transporte de entulhos; limpeza dos logradouros públicos e terrenos baldios; operação de usina de reciclagem de RCC, dentre outras atividades (MACAÉ, 2016).

As atividades de gerenciamento de resíduos provenientes da construção civil em Macaé compõem um cenário que pode ser divido em formal e informal. 0 primeiro setor é representado por empresas privadas gerenciadoras de resíduos que possuem licença ambiental para o desenvolvimento desses trabalhos. Tais empresas devem utilizar o sistema 
de manifestos de resíduos garantindo a destinação e disposição final ambientalmente adequada desses materiais. Já o setor informal é composto por empresas transportadoras não legalizadas, os próprios geradores de resíduos e carroceiros.

0 transporte informal de resíduos por estes agentes sociais ainda permanece no município mesmo diante da publicação da Lei Estadual $n^{0} 7.194$ de 2016. Tal lei proíbe a utilização de tração animal para o transporte de cargas, materiais ou pessoas por quaisquer atos que caracterizem maus tratos.

A falta de informação de empresas e da população sobre o correto gerenciamento dos resíduos é capaz de contribuir significativamente para o aumento dos impactos ambientais (RIBEIR0 et al., 2016). Além disso, o descarte irregular dos RCC's em diversas localidades do município gera um grande gasto de verbas públicas para a manutenção da limpeza urbana.

De acordo com o Instituto de Pesquisa Econômica Aplicada (IPEA, 2012), a elaboração de um diagnóstico deve preceder a implementação de ações que visem a sustentabilidade socioeconômica e ambiental na questão dos resíduos sólidos. Tal etapa deve compreender o reconhecimento da realidade local, regional e nacional; identificação dos tipos de resíduos gerados; levantamento dos aspectos legais e técnicos para só então promover o planejamento de propostas.

Diante do cenário municipal preliminarmente colocado, as estimativas da geração de resíduos foram intercaladas com a identificação de pontos de descartes irregulares na zona urbana gerando o mapa da Figura 1. Para a classificação dos pontos, adotou-se a divisão de bairros do município de acordo com a LCM nº 214/2012. Para as estimativas do quantitativo de resíduos foram utilizados os dados referentes ao ano de 2015, pois os dados de 2016 foram coletados apenas até 0 mês de junho. As estimativas foram apresentadas na forma do índice: toneladas de RCC por hectare da área do bairro, a fim de obter uma proporcionalidade dos resultados para fins de comparação. 
Resíduos da construção civil: cenário atual, planejamento e propostas para o município de Macaé, RJ - Brasil

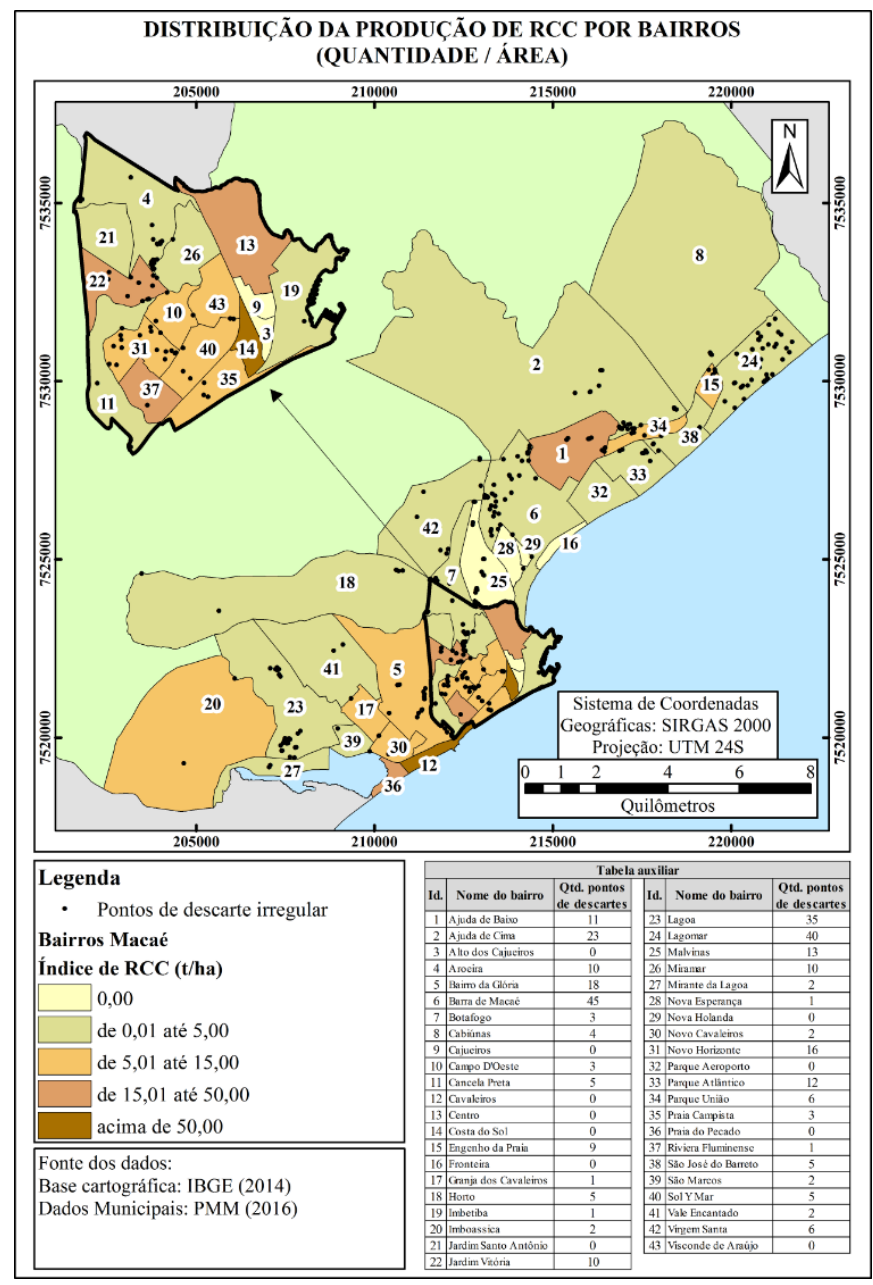

Figura 1 - Mapa dos descartes irregulares e distribuição da estimativa de RCC (t/ha) por bairros.

Fonte: Elaboração própria, 2017.

Foram encontrados 311 pontos de descarte irregular, na maioria dos quais predominam os resíduos das atividades de construção civil. Contudo, nesses locais também são encontrados restos de poda, móveis e até mesmo resíduos domiciliares, apesar da coleta desses últimos abranger todo o município.

É importante ressaltar que tal mapeamento apresenta características dinâmicas, pois os locais utilizados para descartes irregulares são constantemente monitorados pelos serviços de limpeza urbana. Sendo assim, alguns pontos podem deixar de existir ao mesmo tempo em que novos podem surgir, especialmente devido ao fato de que pequenos pontos também foram considerados neste estudo.

A destinação final dos resíduos sólidos na cidade de Macaé ainda se constitui como um problema debatido pelos representantes do poder público municipal. 0s pontos mais críticos são representados pelas dificuldades no controle dos descartes clandestinos de resíduos nas 
ruas, inexistência de políticas públicas eficientes e de aplicação de verbas para 0 desenvolvimento de projetos sociais para geração de emprego e renda (COSTA et al., 2013).

Quanto aos descartes, o modelo de gestão corretiva, geralmente utilizado nos municípios na tentativa de conter a disposição inadequada dos RCC's requer altos custos e ações repetitivas que não solucionam o problema (DELONGUI et al., 2011). As deposições inadequadas geram custos sociais e ambientais que nem sempre são observados pelos gestores, assim como as oportunidades de reaproveitamentos dos RCC's (NUNES, 2004).

De acordo com Plano Municipal de Gerenciamento de Resíduos Sólidos de Macaé (2012), as constantes atividades de recolhimento de resíduos das ruas constituem-se como medidas paliativas do poder público. Tais ações não são eficazes, pois não são capazes de remover a totalidade de resíduos e por fim incentivam a continuidade da disposição irregular nos locais atendidos pela limpeza pública.

0 gráfico 1 indica os quantitativos de resíduos previstos, de acordo com o levantamento das obras formais, para os 10 bairros que apresentaram estimativas acima de 4.000 toneladas/ano para pelo menos um dos anos analisados. Neste gráfico consideram-se as estimativas a partir dos alvarás de construção e demolição emitidos em 2014, 2015 e 2016.

Gráfico 1 - Estimativa de RCC(t) gerados durante os anos de 2014, 2015 e 2016.

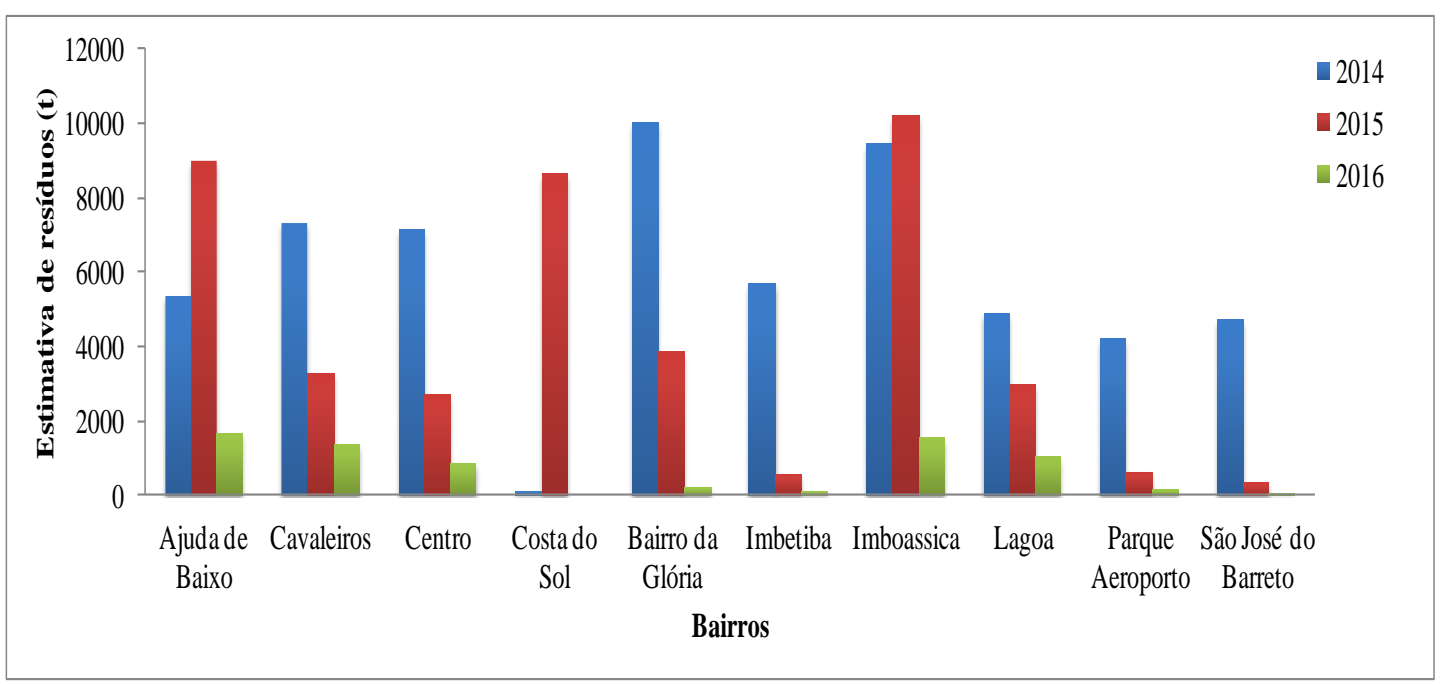

Fonte: Elaboração própria, 2017.

Inicialmente é possível notar que houve uma considerável redução no número de obras regularizadas no ano de 2015 em relação ao ano anterior, o que reflete nos resultados das estimativas de resíduos, de acordo com as metodologias utilizadas. Quanto ao montante dos dados, em 2014 foram emitidos 808 alvarás de construção e em 2015 foram 505, apresentando 
Resíduos da construção civil: cenário atual, planejamento e propostas para o município de Macaé, RJ - Brasil

uma queda de cerca de 37\%. Possivelmente reflexo da crise financeira que se agravou na economia do município neste período. No ano de 2016, até o mês de junho foram emitidos 210 alvarás de construção, proporcionalmente até este período, em 2015 foram 274 e em 2014 foram 415 alvarás de construção.

A partir do gráfico 1 observa-se que os bairros Ajuda de Baixo, Bairro da Glória, Cavaleiros, Centro e Imboassica apresentaram maiores estimativas de geração de resíduos no decorrer do período analisado indicando uma maior ocorrência de construções formais nestes bairros. 0 Bairro da Glória e Ajuda já eram considerados destaques em relação ao crescimento formal no levantamento realizado em 2010 por Sousa (2012) no município objeto de estudo.

Nos bairros com as maiores estimativas predominam as construções de pequeno porte, sendo aquelas classificadas com até 500,00 $\mathrm{m}^{2}$ de área total construída, de acordo com a LCM $n^{0}$ 230/2014. Diante desta informação foi analisada a existência de correlação entre o número de pontos de descarte irregular e o porte das construções, sendo encontrada uma fraca correlação para os anos considerados $2014(\rho=0,212), 2015(\rho=0,212)$ e $2016(\rho=0,153)$. Por outro lado, Almeida (2014) em estudos sobre os RCC's, aponta que muitos pontos de depósitos e despejos desses resíduos são provenientes de pequenas obras e reformas residenciais.

Na figura 2 pode-se observar a zona urbana do município de Macaé dividida em setores administrativos apresentando a estimativa da geração de resíduos para cada um deles. 0s gráficos no mapa indicam as quantidades de alvarás de construção, demolição e os tamanhos das construções. A LCM no $230 / 214$ classifica o porte das edificações em: pequeno $\left(500,00 \mathrm{~m}^{2}\right)$, médio $\left(500,01\right.$ a $\left.2.500,00 \mathrm{~m}^{2}\right)$, grande $\left(2.500,01\right.$ a $\left.5.000,00 \mathrm{~m}^{2}\right)$ e excepcional (igual ou acima de $5.000,01)$ em relação à área total construída. 


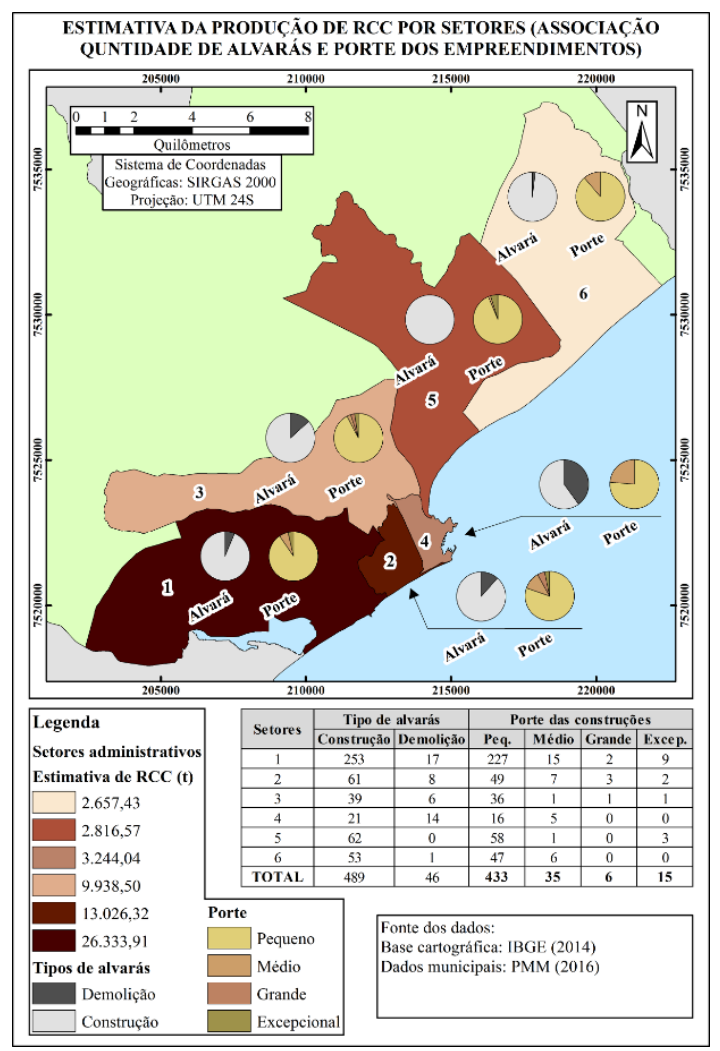

Figura 2 - Mapa da estimativa de RCC (t) em 2016 a partir dos setores administrativos. Fonte: Elaboração própria, 2017.

0 setor administrativo 1 apresentou a maior estimativa de geração de resíduos, com 0 equivalente a 26.333,91 toneladas. Neste setor observa-se as maiores taxas de emissão de alvarás tanto de construção quanto de demolição. Quanto ao porte das edificações predominam aquelas até $500,00 \mathrm{~m}^{2}$, assim como para todos os outros setores.

Dentre os bairros que compõem o setor 1, Lagoa, Imboassica e Jardim Vitória foram os mais representativos quanto à emissão de alvarás de construção correspondendo à 32,81\%, $30,04 \%$ e 12,25\%, respectivamente. Nestes três bairros observa-se uma correlação moderadamente positiva $(\rho=0,49)$ entre a quantidade de obras de pequeno porte e a quantidade de pontos de descarte irregular, apresentados no mapa da figura 2.

Quanto aos demais setores, as maiores estimativas foram encontradas para os setores 2, 5, 4, 3 e 6, em ordem decrescente. 0 setor 2 apresentou aproximadamente metade da estimativa observada para o setor 1, sendo os bairros Sol Y Mar (21,31\%), Novo Horizonte (19,67\%), Riviera Fluminense (18,03\%) e Miramar (16,39\%), com as maiores quantidades de alvarás de construção.

No setor 5 foi encontrada uma estimativa de 9.938,50 toneladas de RCC, sendo este 0 único sem registros de alvarás de demolição. Os alvarás de construção emitidos para os 
Resíduos da construção civil: cenário atual, planejamento e propostas para o município de Macaé, RJ - Brasil

bairros Parque União e Ajuda de Baixo correspondem a 53,23\% e 41,94\% do total do setor. Nestes dois bairros, há uma forte tendência demonstrada pela correlação $\rho=1$ de que quanto mais áreas construídas maior a quantidade de pontos clandestinos de deposição de resíduos.

0 setor 4 é composto pelos bairros Centro, Imbetiba, Cajueiros e Alto dos Cajueiros, sendo que nestes dois últimos não há registros de alvarás de construção ou demolição para 0 ano de 2015. 0 Centro apresenta aproximadamente 71\% dos alvarás de construção e 86\% dos alvarás de demolição emitidos para este setor.

No setor 3 foi observada uma estimativa de resíduos equivalente a 2.816,57 toneladas, sendo os bairros mais representativos Virgem Santa (38,89\%), Horto (27,78\%) e Jardim Santo Antônio (19,44\%), não havendo registros de legalização de obras no bairro Malvinas. Nos primeiros três bairros apontados observa-se uma forte tendência, de acordo com a correlação $\rho=0,96$ de quanto mais obras de pequeno porte, mais o número de pontos de descarte clandestino de RCC.

0 setor 6 apresentou a menor estimativa de geração de RCC, sendo representado pelos bairros Parque Atlântico, São José do Barreto, Lagomar, Parque Aeroporto, Cabiúnas e Engenho da Praia, sendo esses três últimos com 37,73\%, 28,30\% e 26,41\% dos alvarás de construção neste setor, respectivamente.

Relacionando as informações dos dois mapas (figuras 2 e 3), observa-se que os setores $1,2,3,4,5$ e 6 apresentaram respectivamente 79, 38, 37, 1, 86 e 70 pontos de descartes clandestinos de RCC. Analisando as estimativas de geração de resíduos para cada setor, é possível constatar que uma correlação moderada entre esses dois parâmetros, $\rho=0,48$. Entretanto, análises mais detalhadas entre os bairros que compõem estes setores demonstram resultados diferentes.

De acordo com Freesz (2010), até o ano de 1996 os resíduos sólidos urbanos (RSU) de Macaé possuíam como disposição final o lixão denominado Águas Maravilhosas, o qual funcionou por aproximadamente 26 anos. Em 1995, iniciou-se a operação do Aterro Controlado de Cabiúnas. Tal aterro apresentava problemas como o inadequado recobrimento das camadas de lixo causando transtornos para as empresas nos arredores como a proliferação de vetores e transporte de resíduos leves. Diante de problemas técnicos, o órgão estadual emitiu diversas notificações e autos de constatação ao longo dos 13 anos de funcionamento do aterro, o qual teve as atividades encerradas em 2009.

Quanto aos RSU, em fevereiro de 2012, o aterro sanitário da empresa Zadar obteve a Licença de 0peração (L0) No IN018412. A licença autoriza o funcionamento da $1^{\mathrm{a}}$ etapa do aterro 
sanitário para resíduos Classe II e unidade de tratamento de resíduos de serviço de saúde (RSS). Em dezembro de 2015, o aterro teve sua área de operações ampliada a partir da L0 No IN032631 (INEA, 2016).

Em consulta à Secretaria Municipal de Ambiente (SEMA), existem dois aterros particulares licenciados para o recebimento e disposição final de RCC instalados no município. A Central de Tratamento de Resíduos de Construção Civil (CTRCC) da empresa Cabiúnas Terraplanagem obteve em 2011 a Licença Municipal de 0peração (LM0) no 209 que autoriza 0 funcionamento do Centro de triagem e disposição de RCC de classes A, B e C - inertes de acordo com a Resolução CONAMA n ${ }^{0} 307$, em uma área total de $293.831 \mathrm{~m}^{2}$.

No mesmo ano, a Construtora Zadar LTDA obteve a Licença Municipal de Instalação (LMI) no 247 autorizando a implantação da Unidade de Recebimento e Tratamento de RCC, numa área de 17.558,00 m². A licença emitida autorizava, na condicionante de $\mathrm{n}^{0} 27$ a préoperação da unidade. Atualmente, o processo para concessão da LMO da unidade encontra-se em análise no INEA.

Na tabela 1 apresentam-se as estimativas dos resíduos gerados a partir das obras regulares e o comparativo das quantidades recebidas nesses dois aterros.

Tabela 1 - Estimativa de RCC gerados e quantidades recebidas nos aterros em 2014, 2015 e 2016.

\begin{tabular}{lcccccc}
\hline \multicolumn{1}{c}{$\mathbf{2 0 1 4}$} & \multicolumn{2}{c}{$\mathbf{2 0 1 5}$} & \multicolumn{2}{c}{$\mathbf{2 0 1 6}$} \\
\hline Mês & $\begin{array}{c}\text { Estimativa } \\
\text { RCC }(\mathbf{t})^{\star}\end{array}$ & $\begin{array}{c}\text { RCC nos } \\
\text { aterros } \\
(\mathbf{t})^{\star *}\end{array}$ & $\begin{array}{c}\text { Estimativa } \\
\text { RCC }(\mathbf{t})^{\star}\end{array}$ & $\begin{array}{c}\text { RCC nos } \\
\text { aterros } \\
(\mathbf{t})^{\star *}\end{array}$ & $\begin{array}{c}\text { Estimativa } \\
\text { RCC }(\mathbf{t})^{\star}\end{array}$ & $\begin{array}{c}\text { RCC nos } \\
\text { aterros }(\mathbf{t})^{\star \star}\end{array}$ \\
Janeiro & $8.420,89$ & 750,75 & $10.798,76$ & $3.685,65$ & $1.270,78$ & 642,05 \\
Fevereiro & $10.135,51$ & $1.007,29$ & $6.863,98$ & $3.931,64$ & $2.035,46$ & 748,86 \\
Março & $4.474,73$ & $12.046,49$ & $2.689,70$ & $2.175,87$ & $4.270,41$ & 750,50 \\
Abril & $9.817,84$ & $4.254,47$ & $3.831,86$ & $3.427,06$ & $2.169,02$ & 798,46 \\
Maio & $12.723,89$ & $2.504,51$ & $4.473,66$ & $1.651,85$ & $3.085,32$ & 526,97 \\
Junho & $5.925,96$ & $2.812,34$ & $3.141,93$ & $1.592,98$ & - & - \\
Julho & $5.252,44$ & $3.385,67$ & $4.099,12$ & $4.910,89$ & - & - \\
Agosto & $7.671,92$ & $4.773,17$ & $10.268,85$ & $1.714,03$ & - & - \\
Setembro & $11.362,25$ & $4.858,15$ & $2.317,07$ & $1.364,60$ & - & - \\
Outubro & $8.979,48$ & $5.564,54$ & $4.871,06$ & $1.760,24$ & - & - \\
Novembro & $5.394,52$ & $15.497,04$ & $1.146,16$ & 897,67 & - & - \\
Dezembro & $2.481,02$ & $9.304,87$ & $3.514,62$ & 709,31 & - & - \\
\multicolumn{1}{c}{ Total } & $92.640,46$ & $66.759,27$ & $58.016,77$ & $27.821,79$ & $12.830,99$ & $3.466,84$ \\
\hline
\end{tabular}

* Estimativa gerada a partir da equação 1 .

**Soma das quantidades de RCC's recebidos nos aterros das empresas Construtora Zadar e Cabiúnas Terraplanagem.

Fonte: Elaboração própria, 2017. 
Resíduos da construção civil: cenário atual, planejamento e propostas para o município de Macaé, RJ - Brasil

Diante dos resultados apresentados na tabela 1 observa-se que com relação à totalidade dos dados nos anos analisados, as quantidades de resíduos recebidos nos aterros foram menores em relação à estimativa da geração, de acordo com a metodologia utilizada. As potenciais perdas foram de aproximadamente 28\% em 2014, 52\% em 2015 e 73\% em 2016.

De acordo com dados da ABRELPE (2014), a Região Sudeste produz em média 0,746 $\mathrm{kg} / \mathrm{hab} /$ dia de RCC, segundo as estimativas deste mesmo ano. Sendo assim, considerando a população do município de Macaé equivalente a 229.624 habitantes em 2014, de acordo com 0 IBGE, obtém-se uma estimativa de 62.524,31 toneladas geradas no ano de 2014. Tal valor é $32,5 \%$ menor do que a estimativa observada para o ano de 2014 utilizando-se a metodologia proposta por Pinto (1999) e o índice obtido por Llatas (2011). Já em relação ao quantitativo recebido nos aterros, a estimativa obtida pela pesquisa ABRELPE é 6,34\% maior.

Apesar da existência da Unidade de Beneficiamento da empresa Construtora Zadar, a mesma informa que o material britado é utilizado apenas para reforço dos pavimentos dos acessos nas áreas do aterro, não sendo assim gerados agregados reciclados. Como ocorria anteriormente na antiga usina de beneficiamento que funcionou durante os anos de 1995 a 2000 no bairro Novo Horizonte, onde eram produzidos cerca de 1.800 a 2.000 blocos diariamente que eram utilizados nas obras da Prefeitura (MEDEIROS et al., 2016).

Diante do cenário observado no município de Macaé, acredita-se que a proposição de Pontos de Entrega Voluntária (PEV) para o recebimento dos RCC's provenientes de pequenos geradores e Áreas de Transbordo e Triagem (ATT) para grandes geradores seriam capazes de trazer bons resultados na gestão desses resíduos. Com relação ao transporte é necessário promover o cadastramento de empresas gerenciadoras a fim de monitorar a origem dos resíduos gerados, os volumes recolhidos, a destinação e disposição final adequada.

Destaca-se a importância de promover a educação ambiental e fornecer orientações técnicas para gestores municipais, geradores e profissionais autônomos da construção civil, priorizando a não geração de resíduos, conforme a Política Nacional e demais legislações (SÃ0 PAULO, 2014). Considerando a carência de legislações municipais neste assunto, torna-se imprescindivel analisar os dados referentes à gestão dos RCC's em Macaé para a proposição de políticas que estimulem a reciclagem e o uso de agregados reciclados, principalmente nas obras públicas.

Kawatoko e Silva (2015) propõem iniciativas de gestão em três vertentes: pequeno gerador, grande gerador e sustentabilidade. No primeiro caso destacam ações de educação e responsabilidade ambiental, a disponibilização de PEVs, divulgação de canais de denúncia e 
estímulo à fiscalização pelos próprios moradores de bairros atingidos. Para os grandes geradores citam a necessidade de atendimento aos dispositivos legais e maior fiscalização pelo poder público. Por fim a sustentabilidade, é inserida neste contexto para otimização do uso de materiais, redução de desperdícios, reciclagem e consequentemente diminuição do descarte.

Bovea e Powell (2016) apontam a necessidade de realização de estudos para análise dos parâmetros mais críticos no desempenho ambiental de sistemas de gestão de RCC. Devendo-se considerar questões como as distâncias de transporte, consumo de energia, a eficiência da valorização de processos, encargos evitados e dentre outros.

Sendo uma unidade fixa ou móvel, durante o seu planejamento deve-se analisar a possibilidade de estabelecimento de parcerias, priorizando convênios com cooperativas e a realocação dos carroceiros neste mercado. Tais agentes sociais alegam dificuldades financeiras para permanecer na profissão, pois não desenvolvem atividades para complementar a renda e acreditam que os serviços de limpeza urbana realizados pelo município podem ter diminuído a procura por este tipo de transporte. Até o momento os carroceiros informam não terem recebido orientações ou apoio dos órgãos públicos ou outras instituições.

\section{CONCLUSÃO}

Em Macaé, o PMGRS necessita de atualização e, quanto aos RCC’s, se faz necessária a formulação de um plano específico para o gerenciamento desses resíduos. Considerando que a destinação ambientalmente adequada dos resíduos implica em um acréscimo de custos nas obras, torna-se essencial a formulação de políticas públicas diferenciadas para pequenos e grandes geradores.

Para isso é preciso estabelecer uma classificação dos geradores mediante os volumes de resíduos produzidos ou mesmo a partir do porte das construções, já que este parâmetro não consta nas legislações da esfera federal, ficando a cargo dos estados e municípios. Aliado a estas iniciativas, os instrumentos legais também devem aprimorar as políticas de gestão e gerenciamento desses resíduos, prevendo o estímulo à reciclagem e ao uso de agregados reciclados, especialmente em obras públicas. 
Resíduos da construção civil: cenário atual, planejamento e propostas para o município de Macaé, RJ - Brasil

Visto que no município os carroceiros ainda atuam no transporte e destinação dos RCC's, deve-se avaliar a possibilidade de realocação desses agentes e a inserção de cooperativas no âmbito da gestão integrada de resíduos, de acordo com a Política Nacional.

A intensificação da fiscalização ambiental torna-se extremamente relevante para coibir os descartes clandestinos, especialmente nos bairros Barra de Macaé, Lagomar e Lagoa. Neste contexto, a implementação de práticas de educação ambiental é capaz de promover um processo de sensibilização da sociedade atuando em caráter preventivo à degradação ambiental.

A destinação de resíduos aos aterros, apesar de estar de acordo com a legislação caracteriza-se como uma alternativa paliativa, que demanda grandes áreas e desconsidera 0 potencial de reaproveitamento de resíduos recicláveis como matéria prima. No caso de Macaé, o beneficiamento dos RCC's gera produtos com aplicações pouco nobres, visto que estes podem ser utilizados na fabricação de blocos e entre outras estruturas com possibilidade de utilização inclusive em obras públicas, como já ocorreu anteriormente neste município.

Comparando as quantidades de resíduos recebidos nos aterros e as estimativas de geração observa-se que nos três anos analisados, a quantidade de RCC depositados nos aterros de inertes é menor do que o potencialmente gerado pelas obras regulares na zona urbana. Tratando-se de uma estimativa, estes valores de geração são ainda maiores, pois não foi possível mensurar neste trabalho a quantidade de resíduos gerados em obras irregulares. Um dos fatores que podem ter influenciado nessas diferenças é o nível de contaminação dos resíduos recolhidos das ruas ser capaz de inviabilizar a reciclagem e com isso esses materiais acabam destinados ao aterro sanitário.

Diante dos resultados encontrados acredita-se que a proposição de PEVs para entrega de pequenos volumes de RCC e a instalação de ATTs para grandes geradores possam amenizar os problemas de destinação final inadequada no município. Os cenários gerados a partir da divisão de bairros e dos setores administrativos tiveram como objetivo expor os resultados em diferentes perspectivas com o intuito de auxiliar o poder público na gestão desses resíduos e no saneamento dos problemas ambientais relacionados.

\section{REFERÊNCIAS BIBLIOGRÁFICAS}

ABRECON - Associação Brasileira para Reciclagem de Resíduos da Construção Civil e Demolição. Relatório de Pesquisa Setorial 2014/2015: A reciclagem dos resíduos de construção e demolição no Brasil. São Paulo, 2015. Disponível em: <http://www.abrecon.org.br/pesquisa-setorial/>. Acesso em: 30 de maio de 2016. 
ABRELPE - Associação Brasileira de Empresas de Limpeza Pública e Resíduos Especiais. Panorama dos Resíduos Sólidos no Brasil, 2013. Disponível em: 〈http://www.abrelpe.org.br/Panorama/panorama2013.pdf〉. Acesso em: 23 de julho de 2015.

ALMEIDA, N. M. Identificação de deposição clandestina de resíduos de construção civil e demolição na periferia de Goiânia. 2014. 60 f. Monografia (Engenharia Civil) - Universidade Estadual de Goiás. Goiás, Anápolis, 2014.

ÂNGUlO, S. C.; TEIXEIRA, C. E.; CASTRO, A. L. de; NOGUEIRA, T. P. Resíduos de construção e demolição: avaliação de métodos de quantificação. Revista Engenharia Sanitária Ambiental, v.16, n. 3, p. 299-306, jul/set, 2011.

ARAÚJO, D. de L.; FELIX, L. P.; SILVA, L. C.; SANTOS, T. M. Influência de agregados reciclados de resíduos de construção nas propriedades mecânicas do concreto. Revista Eletrônica de Engenharia Civil, v. 11, n. 1, p. 16 - 34, 2016.

BERNARD0, M.; GOMES, M. C.; BRIT0, J. de. Demolition waste generation for development of a regional management chain model. Waste Management, v. 49, p. 156-169, mar. 2016.

BOVEA, M. D.; POWELL, J. C. Developments in life cycle assessment applied to evaluate the environmental performance of construction and demolition wastes. Waste Management, v. 50, p. 151-172, abr. 2016.

BRASIL. Lei Federal $\mathrm{n}^{0}$ 12.305, de 2 de agosto de 2010. Institui a Política Nacional de Resíduos Sólidos; altera a Lei nº 9.605, de 12 de fevereiro de 1998; e dá outras providências. Diário Oficial [da] República Federativa do Brasil, Brasília, DF, 3 ago. 2010. Disponível em: <https://www.planalto.gov.br/ccivil_03/_ato20072010/2010/lei/l12305.htm>. Acesso em: 23 de junho de 2015.

CARDOSO, R.; SILVA, R. V.; BRIT0. J. de, DHIR, R. Use of recycled aggregates from construction and demolition waste in geotechnical applications: A literature review. Waste Management, v. 49, p. 131-145, mar. 2016.

CONAMA. Resolução CONAMA n ${ }^{0}$ 307, de 5 de julho de 2002. Estabelece diretrizes, critérios e procedimentos para a gestão dos resíduos da construção civil. Diário Oficial [da] República Federativa do Brasil, 17 jul. 2002. Disponível em: 〈http://www.mma.gov.br/port/conama/legislacao/CONAMA_RES_CONS_2002_307.pdf〉. Acesso em: 23 de julho de 2015.

COSTA, R. N.; LEAL, G. F.; PEREIRA, C. S. Águas Maravilhosas (Macaé, RJ): do rio ao lixão na memória de uma catadora de lixo. Desenvolvimento e Meio Ambiente, v. 27, p. 109-119, jan./jun. 2013.

DIAS, M. V. Viabilidade de implantação de uma usina de triagem e compostagem de lixo no Município de Macaé. 2011. 72 f. Dissertação (Mestrado em Engenharia Ambiental) - Programa de Pós-Graduação do Instituto Federal de Educação, Ciência e Tecnologia Fluminense, Macaé, 2011.

DELONGUI, L.; PINHEIR0, R. J. B.; PEREIRA, D. da S.; SPECHT, L. P.; CERVO, T. C. Panorama dos resíduos da construção civil na região central do Rio Grande do Sul. Teoria e Prática na Engenharia Civil, n.18, p.71-80, nov. 2011.

FRASSON, S. A.; FILHO, J. A. P. Instalação de um britador de mandíbulas para reciclagem de resíduos de construção civil no município de 0sasco/SP: foco nos aspectos econômicos. Revista Inovação, Projetos e Tecnologias, v. 3 , n. 2. jul./dez. 2015.

FREESZ, N. P. Avaliação das condições da disposição final dos Resíduos Sólidos Urbanos (RSU) do Município de Macaé, Estado do Rio de Janeiro. 2010. 103 f. Dissertação (Mestrado em Engenharia Ambiental) - Programa de PósGraduação em Engenharia Ambiental do Instituto Federal de Educação, Ciência e Tecnologia Fluminense, Macaé, 2010 .

IBGE - Instituto Brasileiro de Geografia e Estatística. Macaé. Disponível em: $<$ http://cidades.ibge.gov.br/xtras/perfil.php?codmun=330240〉. Acesso em: 13 de julho de 2016.

INEA - Instituto Estadual do Ambiente. Pesquisa de processos. Disponível em: 〈http://200.20.53.7/visualizarprocesso/frmPesquisaProcesso.aspx >. Acesso em: 25 de agosto de 2016. 
KAWATOKO, I. E. S.; SILVA, C. H. M. Propostas para a conscientização ambiental sobre o descarte irregular de resíduos de construção civil no município de Campinas. Revista Eletrônica em Gestão, Educação e Tecnologia Ambiental Santa Maria, v. 19, n. 3, p. 595-602, set-dez., 2015.

LLATAS, C. A model for quantifying construction waste in projects according to the European waste list. Waste Management, v. 31, p. 1261-1276, 2011.

MACAÉ. Lei Municipal $n^{0}$ 3.852, de 20 de agosto de 2012. Dispõe sobre objetivos, instrumentos, princípios e diretrizes para o Plano Municipal de Gerenciamento de Resíduos Sólidos no município de Macaé e dá outras providências. Diário da Costa do Sol, Macaé, RJ, 21 ago. 2012. Disponível em: 〈http://sistemas.macae.rj.gov.br:84/transparencia/legislacao〉. Acesso em: 30 de junho de 2016.

Lei Municipal $n^{0}$ 3.371, de 29 de março de 2010. Veda o descarte do lixo doméstico e entulhos em logradouros públicos. Diário da Costa do Sol, Macaé, RJ, 30 mar. 2010. Disponível em: 〈http://sistemas.macae.rj.gov.br:84/transparencia/legislacao〉. Acesso em: 30 jun. 2016.

. Lei Municipal $n^{0}$ 3.743, de 01 de fevereiro de 2012. Dispõe sobre a coleta e distribuição de sobras de material de construção a população carente no município de Macaé e dá outras providências. Diário da Costa do Sol, Macaé, RJ, 03 fev. 2012. Disponível em: 〈http://sistemas.macae.rj.gov.br:84/transparencia/legislaca0〉. Acesso em: 30 jun. 2016.

MEDEIROS, C. R.; SILVA, J. A. F. da. Gestão dos resíduos da construção civil: estudo de caso no município de Macaé, RJ. Boletim do Observatório Ambiental Alberto Ribeiro Lamego, Campos dos Goytacazes/RJ, v.10, n.l, p. 225-251, jan./jun. 2016.

MELO, A. B. de M.; GONÇALVES, A. F.; MARTINS, I. M. Construction and demolition waste generation and management in Lisbon (Portugal). Resources, Conservation and Recycling, v. 55, p. 1252-1264, 2011.

NASCIMENTO, F. A. T.; VIEIRA, A. J. B. BARROSO, I. R. S. LOPES, J. P. Reutilização e reciclagem de resíduos sólidos gerados na construção civil. Ciências exatas e tecnológicas, Maceió, v. 3, n.1, p. 141-152, nov. 2015.

NUNES, K. R. A. Avaliação de investimentos e de desempenho de centrais de reciclagem para resíduos sólidos de construção e demolição. 2004. 297 f. Tese (Doutorado em Ciências em Engenharia de Produção) - Programa de Pós-Graduação de Engenharia da Universidade Federal do Rio de Janeiro. Rio de Janeiro, 2004.

PINTO, T. de P. Metodologia para a gestão diferenciada de resíduos sólidos da construção urbana. 1999. 218 f. Tese (Doutorado em Engenharia) - Escola Politécnica da Universidade de São Paulo, São Paulo, 1999.

PREFEITURA DE MACAÉ. Dados. Disponível em: 〈http://www.macae.rj.gov.br/conteudo/leitura/titulo/dados〉. Acesso em: 12 de julho de 2016.

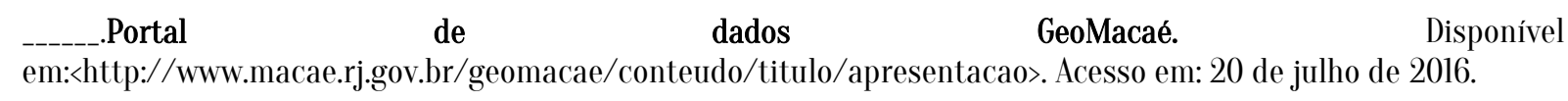

RIBEIR0, D.; MOURA, L. S. de; PIR0TE, N. S. dos S. A. Sustentabilidade: Formas de Reaproveitar os Resíduos da Construção Civil. Revista Cienc. Gerenc., v. 20, n. 31, p. 41-45, 2016.

RI0 DE JANEIR0 (Estado). Lei Estadual n 7.194 , de 07 de janeiro 2016. Dispõe sobre a possibilidade de utilização de animais para fretamento de carroças e charretes no âmbito do Estado do Rio De Janeiro e dá outras providências. Diário Oficial do Estado do Rio de Janeiro, RJ, 08 jan. 2016. Disponível em: <http://alerjlnl.alerj.rj.gov.br/CONTLEI.NSF/c8aa0900025feef6032564ec0060dfff/64le898f0b97ee5283257f34005 86eab?0penDocument>. Acesso em: 25 jul. 2016.

SÃo PAUl0 (Estado). Secretaria do Meio Ambiente. Gerenciamento Online de Resíduos da Construção Civil. Christiane Aparecida Hatsumi Tajiri; João Luiz Potenza. São Paulo: SMA, 2014. 120 f. Série Cadernos de Educação Ambiental. 
SOUSA, J. C. G. de. Urbanização em Macaé: Processo histórico e novos desafios. 2012. 66 f. Trabalho de conclusão de curso (Pós-Graduação lato sensu) Curso de Gestão Pública Municipal/Prefeitura de Macaé. Fundação Educacional de Macaé - FUNEMAC, Faculdade Professor Miguel Ângelo da Silva Santos - FeMASS, Macaé, 2012.

SOUSA, J. S. de; ALVES, G. S. SILVA, A. F. da; SOUSA, G. M. R.; SOBRINHO, A. M. de A. Impacto da construção civil no Produto Interno Bruto brasileiro. Perspectivas on line. Ciências humanas e sociais aplicadas, Campos dos Goytacazes, v. 12, n, 5, p. 25 - 35, 2015.

SOUZA, J. L. Proposta metodológica de cálculo para a pegada hídrica na construção civil imobiliária. 2014. 223 f. Tese (Doutorado em Engenharia Civil) - Programa de Pós-Graduação em Engenharia Civil do Departamento de Engenharia Hidráulica e Ambiental da Universidade Federal do Ceará, Fortaleza, 2014. 